\title{
Bijdrage tot de kennis der inlandsche Zoetwater-Peridineeën
}

DOOR

\author{
H. G. REDEKE
}

(met 6 tekstfiguren)

De Peridineeën behooren tot de weinig bekende eencelligen uit het zoetwaterplankton van Nederland. Opgaven omtrent hun, voorkomen in onze binnenwateren zijn zeldzaam. Daarentegen zijn de in zee levende soorten onzer kust door de onderzoekingen van van Breemen (2) goed bekend. Deze heeft ook enkele brakwatersoorten, meest kleine vormen, uit de Ziuiderzee beschreven. Toch bevat het brakwater wellicht nog meer, tot dusverre nog niet gevonden soorten,

Dat uit ons zoetwaterplankton nog zoo weinig Peridineeën bekend zijn geworden meen ik te moeten toeschrijven aan de omstandigheid, dat men zich tot dusverre bij het planktononderzoek (en dit geldt ook voor het zee- en brakwaterplankton) met het visschen met de bekende planktonnetten heeft vergenoegd. Deze netten, ook die van het allerfijnste builgaas $\left(\mathrm{N}^{0} .25\right)$ vervaardigd, vangen echter bijna uitsluitend de grootere plarkton-organismen en van de kleinere alleen dezulke, die kolonies vormen of van lange uitsteeksels voorzien zijn. Dat fijnste gaas heeft n.l. een maaswijdte van ongeveer $50 \mu$; nauwmaziger kan het niet geweven worden. De grootte massa der planktonorganismen van geringer afmeting dan $50 \mu-$ en dat zijn er, zooals uit tal van recente onderzoekingen gebleken is, niet weinige - ontsnapt door deze mazen. Slechts nu en dan worden er toevallig meegevangen en men heeft dientengevolge langen tijd gemeend, dat die allerkleinste planktonten schaarsch en dus van weinig beteekenis voor de stofwisselingsprocessen in het water waren. Uit onderzoekingen van Kofoid en Lohmann (om alleen de voornaamsten te noemen) is evenwel gebleken, dat. die allerkleinste planktonorganismen, die Lohmann onder den verzamelnaam "nannoplankton" samenvat, zoowel in zee als in het zoete water zeer talrijk zijn en ook een allerbelangrijkste rol spelen, o. a. als voedsel voor grootere planktondieren. Vooral de groep der Phytoflagellaten - en hiertoe behooren de Peridineeën — is in het nannoplankton door een verrassend groot aantal soorten en individuen vertegenwoordigd en vormt, samen met Chlorophyceeën en Diatomeeën, het hoofdbestanddeel daarvan. Het nannoplankton bestaat dus in hoofdzaak uit plantaardige eencellige organismen; de Protozoën spelen in het nannoplankton een ondergeschikte rol.

Voor het verzamelen van dit allerkleinste plankton heeft men aanvankelijk gebruik gemaakt van filters van verschillende dichtgeweven stoffen, waardoor het te onderzoeken water werd gegoten, zoodat het plankton op het filter achterbleef. Het bleek echter, dat aldus. de meestal teere en zeer kleine nannoplanktonten veel te lijden hadden en grootendeels niet dan in verminkten toestand onder het mikroskoop konden worden gebracht. Daarom wordt tegenwoordig het te onderzoeken water gecentrifugeerd en de ervaring heeft 
geleerd, dat zelfs de allerteerste organismen (naakte Flagellaten, Heliozoën e.d.) daardoor niet beschadigd worden. Heeft men voldoende lang gecentrifugeerd, dan kleven de planktonten tegen den bodem van het centrifuge-buisje, zoodat men het water voorzichtig afgieten kan en het plankton in een druppel op den bodem achterblijft. Deze druppel kan met behulp van een pipet worden overgebracht op een objectglas en vervolgens worden onderzocht. De methode leent zich ook goed voor vergelijkend quantitatief onderzoek, indien men n.l. steeds eenzelfde hoeveelheid water, $10 \mathrm{cM}^{3}$ bijvoorbeeld, centrifugeert.

$\mathrm{Bij}$ onderzoekingen, dit voorjaar begonnen, die ten doel hadden na te gaan, of ook in de Nederlandsche wateren het nannoplankton een rol van beteekenis als voedsel voor hoogere planktonorganismen speelt, en in hoeverre het als zoodanig van belang is voor onze binnenvisscherij, bleek mij al spoedig, dat het aantal der organismen, die bij ons in het nannoplankton der binnenwateren voorkomen, verbijsterend groot is, en dat het geen eenvoudige zaak was, die talrijke meestal zeer kleine en dikwijls maar weinig bekende wezens behoorlijk te determineeren. Ik heb mij derhalve voorshands bepdald tot een nauwkeuriger studie van de meest talrijke - en daarom alleen reeds meest belangrijke- - soorten in een bepaald en gemakkelijk af te bakenen gebied: het gebied van het Hollandsch-Friesche laagveen. Bovendien heb ik meer in het bijzonder mijn aandacht gewijd aan een groep van Phytoflagellaten, die mij sterker dan eenige andere aantrok door haar sierlijkheid en verscheidenheid in vorm en levenswijze: de Peridineeën. En omdat het mij voorkomt, dat iedere bijdrage tot de kennis dezer merkwaardige organismen, ook al kan zij, zelfs voor het onderzochte gebied, nog geenszins aanspraak maken op volledigheid, voor verder onderzoek van nut kan zijn, geef ik hier een overzicht van de tot dusver verkregen uitkomsten als eerste bijdrage tot een nauwkeuriger kennis onzer inheemsche zoetwater-peridineeën.

Het onderzochte plankton-materiaal is afkomstig van het Alkmaarder Meer, het Abcouder Meer, de Vecht bij Nigtevecht, de Kortenhoefsche plassen, en, hoewel niet tot het laagveengebied behoorende, het in de duinen bij Callantsoog gelegen Zwanenwater. Verder van de navolgende Friesche meren: het Pikmeer bij Grouw, het Sneeker Meer, de Langweerder Wielen en het Tjeukemeer, benevens enkele kleinere wateren in Friesland. De aard der bovenbedoelde orienteerende onderzoekingen bracht mede, dat op geen der hier genoemde plaatsen van regelmatig met korte tusschenpoozen gedurende een langen tijd voortgezette waarnemingen sprake kon zijn. Omtrent de jaarlijksche periodiciteit der Peridineeën kunnen derhalve eerst latere onderzoekingen licht verspreiden. Een uitzondering maken slechts het Zwanenwater en het Abcouder Meer, waar althans in verschillende jaargetijden plankton verzameld werd en voor sommige soorten bekend is, in welk jaargetijde zij het veelvuldigst voorkomen.

Daar de meeste Peridineeën uit het zoete water tot het nannoplankton behooren en derhalve, met uitzondering van de grootere soorten zooals Ceratium hirundinella, Peridinium tabulatum en enkele andere, niet of slechts onvolledig met het planktonnet gevangen kunnen worden, dient men het water te centrifugeeren. Ik gebruikte daarvoor een kleine handcentrifuge, die gemakkelijk 2000 omwentelingen per minuut maakt en centrifugeerde daarmede steeds eenige malen $10 \mathrm{cM}^{3}$ van het te onderzoeken water gedurende één minuut. Praktisch worden aldus alle in het water aanwezige organismen, de bakterien wellicht uitgezonderd, neergeslagen, gelijk uit contrôle-proeven is gebleken; enkele, die soortelijk lichter zijn dan water, zooals sommige Cyanophyceën, komen aan de oppervlakte drijven. Op den bodem der centrifuge-buisjes vormt zich dan een grooter of kleiner bruin tot groen vlekje, dat eenigen tijd beklijft, zoodat men rustig het buisje leeg kan gieten. Langs den wand laat men. een enkelen druppel terugloopen, men heeft het in de hand, dien druppel naar wensch grooter of kleiner te maken en door even op te schudden kan men in dien eenen druppel al het plankton uit die $10 \mathrm{cM}^{3}$ verzamelen.

Bijna zonder uitzondering heb ik het aldus verkregen materiaal levend onderzocht. Flagellaten, ook Peridineeën, laten zich weliswaar voortreffelijk conserveeren in Flemming's vloeistof en tamelijk wel in formaline $4 \%$, maar in de eerst genoemde vloeistof worden de 
meeste reeds spoedig zwart en dảardoör moeilijk te onderzoeken terwijl de teere, naakte soorten (Gymnodinien) in formol toch wel snel haar vorm en kleur verliezen. Het onderzoek van het levende materiaal is derhalve in ieder geval noodzakelijk, maar het is bij de bewegelijkheid en kleinheid der meeste soorten tijdroovend en vermoeiend. Osmiumzuurdampen per dekglas toegediend worden gezegd verlammend te werken; ik heb dit middel eenige keeren toegepast, doch er niet veel nitwerking van gezien. Een voortreffelijk hulpmiddel bij het onderzoek van Peridineeën is verdunde glycerine: hierdoor wordt de struktuur van het pantser der Peridinium-soorten in vele gevallen verduidelijkt, terwijl het tevens kan dienen om uit te maken, of een soort een omhulsel heeft of naakt is. In het laatste geval n.l. zwelt de cel op, wanneer men verdunde glycerine toevoegt en vloeit ten slotte uiteen, zonder dat er fragmenten van een hulsel achterblijven. De ingewikkelde bouw der pantsers in de geslachten Peridinium, Gonyaulax e. a. kan men het best bestudeeren aan ledige omhulsels, die doorschijnend zijn en dikwijls met de levende exemplaren in het plankton worden aangetroffen.

Van bijna alle waargenomen soorten heb ik schetsen of meer uitvoerige teekeningen vervaardigd, zooals vanzelf spreekt met behulp van een Abbe's teekenprisma, maar ik acht het overbodig hier van elke soort een afbeelding te geven. Alleen voor sommige soorten, die tot dusverre, voor 'zoover ik heb kunnen nagaan, nog niet beschreven of om een andere reden de moeite waard zijn, vindt men enkele afbeeldingen bij de hieronder volgende beschrijvingen.

Zooals bekend is nemen de Peridineeën (Dinoflagellaten) onder de Flagellaten (Mastigophoren) een eigenaardige plaats in, in zoover als er. soorten toe behooren, die chromatoforen bezitten en zich uitsluitend op de wijze der planten voeden, terwijl andere, soms nauw verwante, soorten geen chromatoforen bezitten, er een animale levenswijze op na houden en dus in hoofdzaak "gevormd" voedsel tot zich nemen. Zoölogen en botanici beiden geven derhalve aan de Peridineeën een plaats in hun hand- en leerboeken. Biologisch gesproken behooren de gekleurde Peridineeën tot de producenten, de kleurlooze tot de konsumenten in de levensgemeenschappen, waarvan zij deel uitmaken. De eerstgenoemde vormen echter zoowel in zee als in het zoete water de meerderheid.

De Peridineeën zijn gekenmerkt door het bezit van twee flagellen, die beide ongeveer in het midden van het lichaam ontspringen. Het eene flagellum is in overlangsche richting naar achteren gericht, het andere loopt als een gordel, dwars, rondom het lichaam. Bij sommige soorten is het cel-lichaam naakt - hoogstens is het protoplasma aan de oppervlakte iets steviger, dan in het overige deel der cel - doch bij de meeste is een afzonderlijk omhulsel aanwezig, dat uit een cellulose-achtige stof bestaat en dikwijls het karakter van een uit verschillende platen samengesteld pantser heeft. Hieraan komen vaak verschillende uitsteeksels voor. De beide flagellen komen door een spleet naar buiten en zijn meestal in groeven gelegen: het overlangsche flagellum in een longitudinale groeve (sulcus), het dwarse in een transversale groeve (annulus). De laatste is slechts zelden zuiver equatoriaal, meestal beschrijft zij een spiraalvormige winding om het lichaam.

De typische lichaamsvorm (zooals die bijvoorbeeld in het geslacht Peridinium veelvuldig wordt aangetroffen) kan het best vergeleken worden met dien van een tol, waarvan het borenstuk weinig in grootte verschilt met het onderstuk. De bovenste, apikale lichaamshelft (epivalva) is bij de voortbeweging naar voren gericht en door de dwarsgroeve gescheiden van de achterste, antapikale lichaamshelft (hypovalva). De zijde, waar zich de overlangsche groeve bevindt, wordt buikzijde, de tegenoverliggende rugzijde genoemd. Hieruit volgt, wat rechts en wat links is. Beschrijft de dwarsgroeve een spiraal, dan noemt men haar linkswindend, wanneer zij zich aan de buikzijde links het dichtst bij den apex bevindt. In het tegenovergestelde geval noemt men haar rechtswindend.

Het protoplasma bestaat uit ecto- en entoplasma. In het eerste liggen bij de autotrofe soorten de chromatoforen, die meestal geelbruin of bruingeel, soms groen gekleurd zijn, en dikwijls vet in bolletjes of klompjes. De kleurlooze animale soorten hebben geen chromato- 
foren, doch kleine; ongekleurde lichaampjes, die gewoonlijk als leukoplasten worden aangeduid. Bij vele soorten komt een rood stigma voor, doch dit schijnt niet konstant te zijn. In het entoplasma. liggen de kern en de vacuolen en bij sommige soorten de zgn. "pusulen", met vloeistof gevulde ruimten, die met een fijn kanaal uitmonden in de spleet, waardoor de flagellen naar buiten komen.

De wijze van voortplanting der Peridineeën is nog slechts onvolledig bekend. Bịj verschillende soorten is deeling der vrijlevende, bewegelijke individuen waargenomen (Gymnodinium, Ceratium), bij andere soorten sporenvorming. Alleen bij Ceratium hirundinella is kopulatie waargenomen.

Verreweg de meeste Peridineeën leven planktonisch en bewegen zich schommelend en roteerend om hun lengteas door het water voort. De longitudinale flagel sleept dan achter het lichaam aan. Mariene soorten zijn vaak een hoofdbestanddeel van het plankton; in het zoetwaterplankton spelen zij een meer ondergeschikte rol. Plaatselijk kunnen sommige soorten (Gymnodinium fuscum b.v.) onder gunstige omstandigheden evenwel gedurende korten tijd in grooten getale voorkomen. Onder den naam Cystodinium heeft Klebs een aantal soorten beschreven, die slechts zeer korten tijd (eenige minuten of uren) vrij zwemmen, doch het grootste gedeelte van hun leven in de gedaante van gehoornde cysten doorbrengen. Andere, tot het geslacht Hypnodinium behoorende soorten zijn tot dusverre alleen in rustenden toestrnd bekend. Eindelijk zijn, voornamelijk door Fransche auteurs (Caullery, Chatton e. a.) in de laatste jaren een groot aantal epizoïsche en parasitische, op staarten van Appendiculariers, in eieren van Copepoden en elders levende soorten beschreven.

In het onderhavige opstel worden alleen. vrijlevende, zoetwater-plankton-Peridineeën behandeld.

Het aantal soorten, dat tot dusverre met zekerheid in het Hollandsch-Friesche laagveengebied is waargenomen, bedraagt 12. Zij zijn met enkele twijfelachtige soorten in het onderstaande overzicht systematisch gerangschikt:

\section{Orde: GYMNODINEAE}

Familie: Gymnodiniaccae

1. Gymnodinium aeruginosum Stein.

2. $\quad " \quad$ rufescens (Pénard) Lemm.

3. $\quad$ meervalli nov. spec.

\section{Orde: PERIDINEAE}

Familie: Glenodiniaceae

4. Glenodinium edax Schill.

5. $\quad$ cinctum (Müller) Ehrb.

6. $\quad$ gymnodinium Pénard.

Familie: Peridiniaceae

7. Peridinium tabulatum (Ehrb.) Clap. et Lachm.

8. : $\%$ aciculiferum Lemm.

9. . $\quad$ aciculiferum Lemm. var. abcoudense nov. var.

10. . $"$ laeve Huitfeldt-Kaas.

11. $"$ marssoni Lemm.

12? " latum Paulsen.

13. Diplopsatis spec.

14. Ceratium hirundinella (O. F. M.) Schrank. 


\section{GYMNODINIUM}

1. G. aeruginosum Stein.

Organismus, III, 2, pl. II, figg. $19-21$.

Syn. G. viride Pénard.

Péridiniacées, blz: 55, pl. IX, figg. 11-24.

Lichaam eivormig, in dwarsdoorsnede bijna rond, alleen aan de buikzijde eenigszins afgeplat. Antapikale gedeelte duidelijk grooter dan het apikale. Dwarsgroeve zwak linkswindend, overlangsche groeve ondiep, niet of slechts weinig overgaand op het apikale gedeelte. Chromatoforen klein, schijfvormig, helder blauwgroen, aan de periferie minder talrijk dan in het overige gedeelto van het lichaam, kern groot, stigma nu eens duidelijk, dan week onduidelijk of afwezig.

Lengte: $2 \gamma-28 \mu$, breedte: $21-23 \mu$.

Vindplaatsen: Pikmeer bij Grouw, Langweerder Wielen, Sluiskanaal bij Nigtevéecht. Centrifuge- en (zeldzaam) netplankton.

Ofschoon de door mij gevonden blauwgroene Gymnodinien in sommige opzichten afwijken van de door von Stein (l. c.) beschreven en afgebeelde $G$. aeruginosum, heb ik toch gemeend ze alle als behoorende tot deze soort te moeten beschouwen. Grootte van het lichaam, vorm, kleur en ligging der chromatoforen komen overeen met von Stein's aeruginosum, mair de gedaante is eenigszins anders. In de eerste plaats is bij mijn exemplaar de antapikale helft grooter dan de apikale, terwijl bij von Stein de verhouding juist omgekeerd is. Verder zijn de door von Stein afgebeelde exemplaren dorsoventraal sterk afgeplat: bij mijn exemplaren is de dwarsdoorsnede vrijwel rond. Ook is de overlangsche groeve lang zoo duidelijk niet als von Stein haar teekent en bovendien zoo goed als geheel tot de antapikale buikzijde beperkt. Hier bevindt zich bij mijn exemplaren ook de celkern, terwijl von Stein haar juist in het voorste, apikale, gedeelte afbeeldt. Eindelijk ontbreekt bij von Stein de oogvlek, terwijl ik deze in mijn exemplaren nu eens duidelijk, dan weer niet of twijfelachtig vond.

Ten opzichte van deze laatste bijzonderheid komen de Nederlandsche exemplaren overeen met de door Pénard (l. c.) beschreven $G$. viride uit het meer van Genève. Schilling (10) houdt de laatste voor dezelfde soort als $G$. aeruginosum en ik meen terecht. Weliswaar geeft Pénard niet op, dat zijn soort blauwgroen is, maar voor het overige past zijn beschrịving zeer wel op de door von Stein afgebeelde exemplaren. Hier is dan van belang hetgeen Pénard zegt over het stigma en de kern: "tâche oculaire fréquente, noyau normal à position très variable" (l. c., blz. 55).

De verschillende opgaven omtrent de afmeting van dezen Gymnodinium komen goed overeen met de door mij gevonden grootte: Pénard geeft voor de lengte op $35 \mu$, voor de breedte $25 \mu$, Schilling $33-34 \mu$ resp. $21-22 \mu$.

De door Schilling vermelde "Gallerthülle" heb ik vaak bij afstervende exemplaren waargenomen: „umfangreich" was zij evenwel nooit - hoogstens enkele mikra dik.

2. G. rufescens (Pénard) Lemm.

Hedwigia, XXXIX, 1900, blz. 116 .

Syn. G. mirabile var. rufescens Pénard.

Péridiniacées, blz. 5\%, pl. V, figg. 8-9.

Lichaam eivormig, in dwarsdoorsnede rond. Antapikale gedeelte ongeveer even groot als het apikale, beide breed afgerond. Dwarsgroeve duidelijk linkswindend, overlangsche groeve diep, tot aan het achterste uiteinde en ook een eind op de apikale helft doorloopend. Chromatophoren langwerpig, bruingeel, ook aan de periferie, kern in het antapikale gedeelte, geen stigma.

Lengte: $39-41 \mu$, breedte: $25-27 \mu$.

Vindplaatsen: Abcouder Meer, Vecht bij Nigtevecht. Centrifuge-plankton. 
Een Gymnodinium, die in het voorjaar $191 \%$ tamelijk algemeen in het Abcouder Meer voorkwam, heb ik gemeend tot deze soort te moeten brengen, want, ook al wijkt zij in sommige opzichten af van de tot dusver gepubliceerde beschrijvingen, toch vertoont zij met geen andere soort grooter overeenkomst. Alleen is bij mijn exemplaren het lichaam meer gestrekt en loopt de overlangsche groeve iets minder ver door op het apikale gedeelte, dan op de afbeelding van Pénard (cf. in het bijzonder fig. 9). Na de deeling nog samenhangende individuen heb ik bij herhaling gezien; bij geen andere soort schijnen zulke paartjes zoo regelmatig voor te komen.

Volgens Pénard is deze Gymnodinium, dien hij als een varieteit van de veel grootere en geheel anders gebouwde $G$. mirabile Pénard beschouwt, $45 \mu$ lang en $40 \mu$ breed - nadert dus meer den bolvorm dan de door mij gevonden exemplaren.

Evenals bij de voorafgaande soort ontstaat bij afstervende exemplaren een geleiachtig omhulsel, dat het geheele lichaam met een doorschijnende, slechts enkele $\mu$ dikke laag bedekt.

(In gezelschap van dezen Gymnodinium vond ik in het Abcouder Meer nog een andere, die groote overeenkomst had met G. Zachariasi Lemm. Daar de enkele exemplaren, die ik kon onderzoeken, niet toelieten de soort met zekerheid te bepalen, vermeld ik haar hier slechts voorloopig).

3. G. meervalli nọ. spec. $\left.{ }^{1}\right)$.

Lichaam lang omgekeerdtolvormig, in dwarsdoorsnede bijna rond, ventraal iets afgeplat. Antapikale gedeelte kleiner dan het apikale, laag-kegelvormig met spitsen punt, vaak met

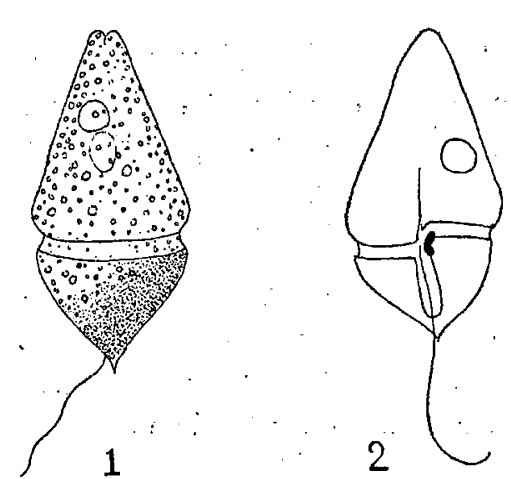

Gymnodinium meervalli nov. spec.

Fig. 1. Een individu van de rugzijde gezien met eenigszins ingedeukten apex en stekelpuntje aan den antapex. - Fig. 2. Een ander individu van de buikzijde gezien, zon-
der duidelijk stekelpuntje. - Verg. 820 . een stekelpuntje, antapikale helft hoog-kegelformig met stompen, eenigszins bewegelijken top. Dwarsgroeve diep, dujdelijk linkswindend, overlangsche groeve weinig diep, onduidelijk, zich uitstrekkend als een vlakke, bijna lijnvormige gleuf tot ongeveer op de helft van het apikale deel. Chromatoforen ontbreken, in de plaats daarvan kleine, ronde, kleurlooze korrels (leukoplasten?) in het perifere protoplasma, kern groot, in het apikale gedeelte, stigma groot, helder-karmijnrood. 'De grootste rechterhelft van het antapikale gedeelte donker-paarsbruin gekleurd. Figuur 1 en 2.

Lengte: $40-42 \mu$, breedte $22-24 \mu$.

Vindplaatsen: Langweerder Wielen, Tjeukemeer. Centrifuge-plankton.

Deze fraaie en zeer kennelijke, tot dusverre nog niet be-

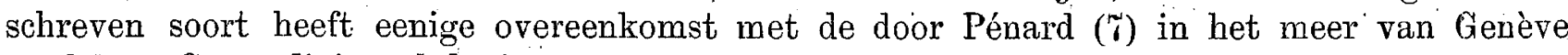
ontdekte Gymnodinium helveticum, doch onderscheidt zich daarvan voornamelijk door haar kleur, het bezit van een stigma en het gemis van de drie spitsen op den antapex.

Bij $G$. helveticum, ,le corps tout entier est d'une rose fleur de pêcher, très claire mais normale" (l. c. blz. 59). Mijn nieuwe Gymnodinium heeft een eenigszins grauwe kleur met uitzondering van het rechter gedeelte der achterhelft (zie fig.), dat donker-paarsbruin, soms eenigszins vuilbruin gekleurd is. De grauwe tint wordt veroorzaakt door talrijke kleine korreltjes, die bij een zwakke vergrooting den indruk maken van pigmentvlekjes, die over het geheele lichaam verspreid zijn. Waardoor de donkerbruine kleur veroorzaakt wordt, kan ik niet met zekerheid zeggen. Kleurstoflichamen zijn er niet; veeleer lijkt het, alsof zich onder de oppervlakkige protoplasmalaag een amorfe kleurstof heeft opgehoopt. Drukt men de cel stuk of laat men haar in verdunde glycerine uiteengaan, dan blijft het donkerbruin gekleurde als een los samenhangende massa bestaan, waarin geen structuur valt waar te nemen. De eigen-

1) Aldus genoemd naar ons drijvend laboratorium, de ",Meerval”. 
aardige verdeeling van licht en donker maakt, dat deze soort ook met zwakke vergrooting reeds gemakkelijk herkend wordt.

Vervolgens bezit deze Gymnodinium een fraai, langwerpig, helder-karmijnrood stigma aan de buikzijde op de plaats, waar de overlangsche en dwarsgroeve samenkomen (zie fig. 2), terwijl Pénard van zijn soort uitdrukkelijk vermeldt: „la tâche oculaire n'existe pas" (1. c. blz. 59).

Eindelijk beschrijft Pénard bij zijn soort, sprekende over den vorm van het antapikale gedeelte: „autour de la pointe centrale un petit relief circulaire, qui se présente à gauche et à droite comme une pointe" (l. c. blz. 58, noot), - ex is dus eigenlijk maar één punt. Bij mijn Gymnodinium is de punt van het antapikale gedeelte spits en geenszins door zulk een walletje omgeven. Daarentegen vond ik dikwijls, nu eens meer, dan weer minder duidelijk, een klein hyalien stekelpuntje (zie fig. 1), soms flauw gebogen, maar altijd precies op den top van het antapikale gedeelte.

Zeer karakteristiek voor deze soort is het voorste uiteinde, dat soms eenigszins ingedeukt schijnt, een geringe maar duidelijke bewegelijkheid bezit en onder het zwemmen nu eens eenigszins gekromd, dan weer recht is. Ook bij stilliggende individuen kan de beweging van den top worden waargenomen, en het maakt den indruk alsof het dier er mee tast. De voortbeweging is gelijkmatig, tegelijkertijd schommelend en tollend, zooals bij vele Flagellaten. Het overlangsche flagellum is fijn, maar niet buitengewoon lang, het dwarsflagellum verraadt zijn aanwezigheid op de gewone manier, n.l. door golvende trilling in de dwarsgroeve.

Evenals $G$. helveticum is deze soort gekenmerkt door het gemis van chromatoforen: zij neemt derhalve reeds gevormd voedsel tot zich. Waaruit dit bestaat heb ik niet met zekerheid kunnen uitmaken, aangezien de door mij onderzochte exemplaren, slechts onherkenbare voedselresten bevatten.

Ik vond deze soort tot dusver alleen in Friesland en wel het eerst in Augustus in de Langweerder Wielen, later ook in het Tjeukemeer, in het centrifuge-plankton, op diepten van 0.5 tot ongeveer $2.0 \mathrm{M}$., regelmatig doch nooit zeer talrijk, n.l. $\mathbf{3}-\mathbf{5}$ exemplaren per $10 \mathrm{eM}^{3}$ water.

(Bij de vergelijking van mijn figuren met die van Pénard met name pl. V, figg. 10, 11, 13, dient men in het oog te houden, dat Pénard de gewoonte heeft, zijn Peridineeën het onderste boven af te beelden! Vandaar dat de spitse voorhelft, het deel dat bij de voortbeweging naar voren is gericht, in de genoemde figuren van $G$. helveticum naar beneden geteekend is. Pénard houdt, natuurlijk, desniettegenstaande apikale en antapikale helft goed uit elkaar, maar zoowel Lemmermann (4), als Schilling (10), die beiden figuren van $G$. helveticum reproduceeren in den stand waarin Pénard ze oorspronkelijk gaf, houden met deze bijzonderheid geen rekening, maar beschrijven de antapikale helft als het voorste, de apikale helft als het achterste gedeelte van $G$. helveticum! Hun beschrijvingen zijn derhalve verward en gedeeltelijk onjuist. Soortgelijke slordigheden komen vooral in het boekje van Schilling bij herhaling voor en verminderen de bruikbaarheid er van in niet geringe mate).

\section{GLENODINIUM}

\section{G. edax Schill.}

Ber. deutsch. bot. Gesellsch. IX, 1891, blz. 206, pl. X, figg. 23-24.

Lichaam bijna bolvormig, doch iets minder hoog dan breed, in dwarsdoorsnede rond. Apikale helft stomp-kegelvormig, grooter dan het bijna halfbolvormige antapikale deel. Dwarsgroeve zwak linkswindend, overlangsche groeve, ver naar achteren loopend, niet op de voorste lichaamshelft overgaand. Chromatoforen ontbreken, in de plaats daarvan komen niet zeer talrijke, heldere korrels voor (leukoplasten?), kern groot, in de achterste lichaamshelft, geen stigma.

Lengte: $24-26 \mu$, breedte: $26-28 \mu$.

Vindplaats: Langweerder Wielen. Centrifuge-plankton. 
Deze zeer kennelijke kleurlooze soort is door mij in Augustus regelmatig, doch altijd, sporadisch, in de Langweerder Wielen aangetroffen, meestal in gezelschap van de voorafgaande. Het uitwendig voorkomen mijner exemplaren beantwoordde bijna geheel aan de door Schilling gegeven beschrijving; alleen waren zijn exemplaren grooter en ook iets langer dan. breed n.l. $34 \mu$ bij $33 \mu$; dus minder gedrongen dan de Langweerder vorm.

(Een tweede kleurlooze Glenodinium-soort, kleiner en ronder, dan de voorafgaande n.l. $22 \mu$ bij $22 \mu$,-wier beide helften halfbolvormig en even groot waren, is in het voorjaar; talrijk in het centrifuge-plankton van het Abcouder Meer. Zij voedt zich daar bijna uitsluitend met de in het voorjaar eveneens zeer talrijke Chrysomonadine Chrysococcus rufescens. Klebs. Zij heeft in vele opzichten gelijkenis met Gl. pulvisculus (Ehrenb.) Stein, doch de laatste bezit bleekgele chromatoforen, terwijl die kleine Glenodinium van Abcoude, zooals gezegd, kleurloos is. Of wij hier een nieuwe soort voor ons hebben dan wel een nog kleineren vorm van $G l$. edax kan eerst door een voortgezet onderzoek worden uitgemaakt).

5. Gl. cinctum (Müller) Ehrb.

Infusionsth., blz. 25\%, taf. XXII, tig. 22.

Lichaam bijna bolvormig, dorsoventraal iets afgeplat. Apikale gedeelte halfbolvormig, nagenoeg even groot als het meer kegelvormige antapikale gedeelte. Dwarsgroeve zwak linkswindend, overlangsche groeve diep, tot ver naar achteren loopend, niet op het apikale gedeelte. Chromatoforen helder bruingeel, kern centraal gelegen, stigma rood, eenigszins hoefijzervormig.

Lengte: 30 tot $33 \mu$, breedte: $28-30 \mu$.

Vindplaatsen: Langweerder Wielen, Tjeukemeer.

De exemplaren van deze soort, die ik tot dusver in onze wateren heb aangetroffen, waren alle kleiner dan gewoonlijk wordt opgegeven (lengte $43-45 \mu$ ), terwijl ook de oogvlek minder duidelijk hoefijzervormig was, dan zij veelal wordt afgebeeld. Toch twijfel ik er niet. aan, of zij behooren tot deze soort, die een zoo kennelijke gedaante heeft en zich van Gl. pulvisculus, waarop zij overigens sterk gelijkt, door het bezit van een fraai robijnrood stigma onderscheidt. Bij de door Ehrenberg afgebeelde exemplaren, die ook in latere monographien (zoo bij Lemmermann 4; blz. 580) zijn gereproduceerd, is het stigma groot en ruw hoefijzervormig. Bij mijn exemplaren was het stigma naar verhouding. kleiner en nooit duidelijk hoefijzervormig, wel vaak onregelmatig of rondachtig. Overigens ontbreekt het stigma bij de door Pénard afgebeelde Gl. cinctum geheel, ook in zijn beschrijving maakt.hij er geen melding van.

Nog in een ander opzicht wijken mijn exemplaren eenigszins af zoowel van die van Ehrenberg als van Pénard. De vorm is zooals de laatste die beschrijft: „turbiforme, faiblement mais regulièrement arqué en ogive à la partie antérieure, creusé un contraire à l'extrémité postérieure d'une dépression médiane à peine sensible (quelquefois nulle)" maar deze "dépression" is bij sommige der Langweerder exemplaren zóó diep, dat de antapex duidelijk naar binnen gebogen is.

Deze soort schijnt wel heel variabel te zijn, zoowel wat grootte als inwendigen bouw aangaat. Lemmermann (l.c.) is er dan ook toe overgegaan een drietal vormen, die door Stein, Bergh en Dangeard als $G l$. cinctum beschreven zijn als zelfstandige soorten te beschouwen, waaraan hij de namen Gl. Steinii, Gl. Berghii resp. Gl. Dangeardii heeft gegeven. In hoever dit gerechtvaardigd is, kan eerst door voortgezet onderzoek aan een grooter materiaal van verschillende vindplaatsen. worden uitgemaakt.

6. Gl. gymnodinium Pénard.

Péridiniacées, blz. 54, pl. IV, figg. 8-10.

Lichaam van voren gezien rondachtig, van terzijde gezien eenigszins spoelvormig, aan 
de buikzijde sterk ingedeukt. Apikale helft plat kegelvormig, antapikale helft meer afgerond, beide ongeveer even groot. Dwarsgroeve diep en sterk linkswindend, langsgroeve diep, naar achteren verwijd, alleen op het antapikale gedeelte. Chromatoforen klein, rond, geelbruin, kern in de achterste lichaamshelft, stigma groot, langgestrekt en donker-karmijnrood.

Lengte: $40 \mu$, breedte: $35 \mu$ (volgens Pénard).

Viudplaatsen; Langweerder Wielen, plas bij Laaxum. Centrifuge-plankton.

Een door haar platte gedaante zeer kennelijke soort, waarvan ik echter tot dusverre slechts twee exemplaren heb gevonden: één in de Langweerder Wielen en één in een plas bij Laaxum (Friesland), beide keeren in centrifuge-plankton. Daar ik deze Glenodinien alleen levend gezien heb en zij mij daarna ontsnapt zijn, ben ik niet in de gelegenheid geweest ze nauwkeurig te meten of te teekenen. Slechts in een enkel opzicht weken mijn exemplaren af van die vạn Pénard: terwijl deze vermeldt, dat de "tâche oculaire" normaal is, en haar als een niervormig lichaampje, in de voorste lichaamshelft gelegen, afbeeldt, bezaten mijn exemplaren beide een zeer opvallend gekleurd, langwerpig stigma, dat op de gewone plaats, daar waar de overlangsche groeve in de dwarsgroeve uitmondt, wordt aangetroffen. De kern was bij mijn exemplaren onduidelijk.

\section{PERIDINITM}

\%. P. tabulatum (Ehrb.) Clap. et Lachm.

Études sur les infusoires, blz. 403.

Syn. Glenodinium tabulatum Ehrb. apiculatum Ehrb.

Infusionsth., blz. $25 \%$, pl. XXII, figg. 23 resp. 24.

Lichaam eivormig, dorsoventraal afgeplat. Apikale gedeelte klokvormig, veel grooter dan het meer half-bolvormige antapikale gedeelte. Het pantser van het eerste bestaat uit 14 platen n.l. 7 prae-aequatoriale, 1 ruitvormige en 6 apikale, het pantser van het achterste gedeelte bestaat uit $y$ platen (het normale aantal) t. w. 5 post-aequatoriale en 2 antapikale. De platen vertoonen een duidelịjke netvormige struktuur en zijn met stekeltjes bezet. Dwarsgroeve linkswindend, overlangsche groeve op de voorste lichaamshelft beginnend, naar achteren toe iets breeder wordend. Chromatoforen geelbruin, geẹn stigma.

Lengte: $45-55 \mu$, breedte: $35-50 \mu$.

Vindplaats: tot dusver alleen met zekerheid in het Zwanenwater bij Callantsoog. Neten centrifuge-plankton in de zomermaanden. Komt waarschijnlijk ook elders in ons land veel voor.

\section{P. aciculiferum Lemm.}

Ber. deutsch. bot. Gesellsch. XVIII, 1900, blz. 28.

Lichaam eivormig, dorsoventraal afgeplat. Beide lichaamshelften ongeveer even groot, kegelvormig, de antapikale helft iets meer afgerond, met drie stekeltjes, waarvan het eene op den antapex, de beide andere links en rechts daarvan zitten. Het pantser van de voorste lichaamshelft bestaat uit 13 platen, n.l. $\%$ prae-aequatoriale, 1 ruitvormige en 5 apikale, het pantser der achterste lichaamshelft nit 7 platen n.l. 5 post-aequatoriale en twee even groote antapikale. De platen bezitten een fijne netvormige struktuur, de ribben zijn smal. Dwarsgroeve duidelijk linkswindend, overlangsche groeve naar achteren ver doorloopend, door een fijne dwarsnaad in tweeën gedeeld, slechts even op de voorste lichaamshelft beginnend. Chromatoforen bruingeel, schijfvormig, kern centraal eenigszins niervormig, geen stigma.

Lengte: : 35-40 $\mu$; breedte: $27-32 \mu$.

Vindplaats: Zwanenwater bij Callantsoog. Net- en centrifuge-plankton. Maart, zeer talrijk.

Deze soort, die met de voorafgaande tot de meest verspreide Peridineeën behoort, en waarschijnlijk ook elders in ons land veelvuldig voorkomt, heb ik tot dusverre met zekerheid 
alleen in het Zwanenwater gevonden. Zij is gemakkelijk te herkennen aan de door een fijne dwarsnaad verdeelde overlangsche groeve en bereikt volgens Lemmermann (4) het maximum harer ontwikkeling in het koude jaargetijde.

9. P. aciculiferum Lemm. var. abcoudense nov. var.

Lichaam ei-bolvormig, in dwarsdoorsnede bijna rond, met duidelijken apex. Apikale helft
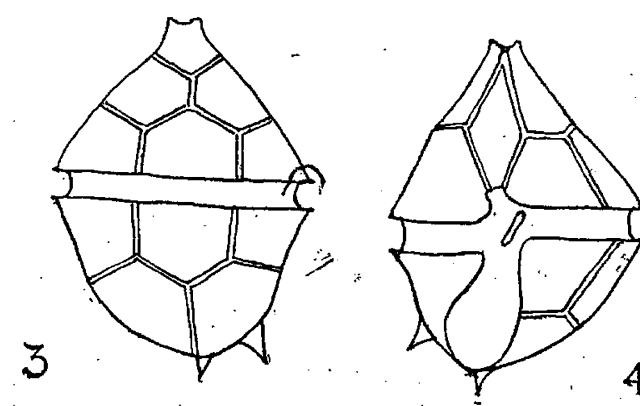

Peridinium aciculiferum Lemm. var. abcoudense nov, var.

Fig. 3. Een individu van de rugzijde gezien. Fig. 4. Een ander individu van de buikzijde en eenigszins. van links gezien. - Vergr. 780. bol-kegelvormig, iets toegespitst, antapikale helft koepelvormig mit twee stekeltjes, waarvan het eene op den antapex; het andere rechts daarvan zit. Het pantser van de voorste lichaamshelft bestaat uit 13 platen, n.l. 7 prae-aequatoriale, 1 ruitvormige en 5 apikale, het pantser der achterste lichaamshelft met 7 platen (het gewone aantal) n.l. 5 post-aequatoriale en 2 ongeveer even groote antapikale. De platen zijn glad, de ribben smal en aan levende exemplaren moeilijk te zien. Dwarsgroeve breed, linkswindend, overlangsche groeve naar achteren ver doorloopend en verbreed zonder dwarsnaad, slechts even. op de voorste lichaamshelft beginnend. flagellenspleet bijzonder duidelijk. Chromatoforen groot, langwerpig, helder-bruingeel, kern centraal, geen stigma. - Figuur 3 en 4.

Lengte: $45 \mu$, breedte: $33 \mu$.

Vindplaats: Abcouder Meer. Net- en centrifuge-plankton.

Deze fraaie en levendig gekleurde Peridinium vond ik in de maanden Maart en April vrij talrijk in het Abcouder Meer, later in het jaar slechts sporadisch. Hij behoort derhalve tot de voorjaarsvormen.

De gedaante en rangschikking der pantserplaten vertoont een zoo groote overeenkomst met die van $P$. aciculiferum Lemm. dat er niet aan valt te twijfelen, of wij hebben hier met een varieteit van deze soort te doen, die in sommige kenmerken, voor zoover ik heb kunnen nagaan regelmatig, afwijkt van Lemmermann's soort. De verschillen zijn de volgende: terwijl bij $P$. aciculiferum de overlangsche groeve door een fijne dwarsnaad in twee helften is verdeeld, ontbreekt deze naad bij var. abcoudense. Vervolgens komen bij de soort 3 lijstvormige dorentjes aan het antapikale uiteinde voor, terwijl ik bij de nieuwe var. er nooit meer dan twee heb gevonden. Eindelijk vormen de hoekpunten der ribben aan den apex een sierlijk tuitje, dat eenigszins aan een schoorsteentje doet denken, doch bij de oorspronkelijke soort niet of niet in die mate tot ontwikkeling komt. Ook de omstandigheid, dat ik deze var. alleen in de maanden Maart en April in eenigszins grootere hoeveelheden aantrot, pleit voor de nauwe verwantschap met $P$. aciculiferum, die ook als een voorjaarsvorm bekend staat (cf. . Ostenfeld 5, blz. 391).

\section{P. laeve Huitfeldt-Kaas.}

Krist. Vid. Selsk. Skr. I. Math. nat. Kl. 1900, 2, figg. 1-5.

Lichaam eivormig. Apikale helft spitser en iets grooter dan de nagenoeg half-bolvormige antapikale helft. Het pantser van de voorste lichaamshelft bestaat uit 13 platen, n.l. 7 ongeveer even breede prae-aequatoriale, een kleine ruitvormige en 5 apikale platen, waarvan de op den top liggende bijna vierkant is, het pantser der achterste helft uit het gewone aantal: 7 . De platen zijn glad, doch op de hoeken der polaire platen komen kleine stekeltjes voor. De dwarsgroeve is breed en sterk linkswindend, de overlangsche groeve begint even op de voorste lichaamshelft en loopt op de achterste, sterk verbreed met onregelmatige, bochtige randen ver naar achteren, bijna tot aan den antapex.

Lengte: $46 \mu$, breedte: $40 \mu$.

Vindplaats: Zwanenwater bij Callantsoog. Netplankton, in Maart, veelvuldig. 
Daar ik deze soort tot dusverre alleen in geconserveerden toestand heb onderzocht kan ik omtrent kleur en vorm der chromatoforen, de ligging van den kern en het al of niet voorkomen van een stigma niets met zekerheid mededeelen. Mijn exemplaren waren kleiner, dan die van Huitfeldt-Kaas, die $52 \mu$ voor de lengte en $44 \mu$ voor de breedte opgeeft, doch iets grooter dan de door Zacharias gevondene, die $42 \mu$ lang en $33 \mu$ breed waren (Zacharias 12 , blz. 210).

\section{P. marssonii Lemm.}

Ber. deutsch. bot. Gesellsch. XVIII, 1900, biz. 28.

Lichaam bijna bolvormig, dorsoventraal eenigszins afgeplat. Beide lichaamshelften nagenoeg even groot, de voorste iets kegelvormig, de achterste meer rond. Het pantser der voorste helft is sterk asymmetrisch en bestaat uit slechts 11 platen, n.l. $\%$ prae-aequatoriale, 1 naar links geschoven ruitvormige en 3 apikale platen: het pantser van de achterste lichaamshelft bestaat als gewoonlijk uit $\gamma$ platen, waarvan de linker antapikale iets grooter is dan de rechter. De platen zijn konkaaf, waardoor het lichaam ingedeukt lijkt, en hebben hooge randen, die dicht met fijne stekeltjes bezet zijn. De ribben zijn tamelijk breed. De dwarsgroeve is duidelijk linkswindend, de overlangsche groeve begint even op de voorste lichaarnshelft en loopt iets verbreed met gladde randen tot ver naar achteren door.

Vindplaats: Zwanenwater bij Callantsoog. Netplankton, Maart, zeldzaam.

Van dezë gemakkelijk te herkennen soort vond ik tot dusverre slechts een exemplaar in het Zwanenwater, dat ik evenwel verzuimde te meten. Volgens Lemmermann (l. c.) bedraagt de lengte: $4 \%-50 \mu$, de breedte: $40-42{ }^{\prime} \mu$.

\section{2? P. latum Paulsen}

Nordisches Plankton, XVIII, 1908, blz..41, fig. 48.

Sijn. Glenodinium acutum Apstein.

Süsswasserplankton, 1896 , blz. 152 , fig. 54 .

Diplopsalis acuta Entr. fil.

Res. wiss. Erf. Balatonsee, II, 1, blz. 12, fig. 5 a-r.

Een Peridinium, die in zijn geheelen habitus de grootste overeenkomst had met de hierboven genoemde soort, komt in het najaar vrij veel in het Alkmaarder. Meer (brak water!) voor. Daar ik hiervan tot dusver echter alleen gefixeerd materiaal kon onderzoeken en deze niet de chocoladebruine kleur bezaten, die als kenmerkend voor deze soort wordt opgegeven, ben ik nog niet geheel zeker van de juistheid mijner determinatie en vermeld ik haar hier slechts onder voorbehoud.

\section{DIPLOPSALIS}

13. D. spec.

Een kleurlooze Diplopsalis-soort, $3 \%-40 \mu$ lang, $40-43 \mu$ breed, $\pm 35 \mu$ dik (figuur 5 en 6) die zoowel met $D$. caspica Ostenf. als met $D$. pillula Ostenf. veel overeenkomst vertoont, komt des zomers in sommige Friesche meren (Langweerder Wielen, Tjeukemeer) tamelijk veel voor. Van de eerstgenoemde soort verschilt zij o: a. door de ver naar achteren loopende overlangsche groeve met sterk ontwikkelden linker randvleugel, die met zijn eenigszins gekromd uiteinde tot voorbij den antapex uitsteekt. Van de laatstgenoemde soort, waar deze vleu-

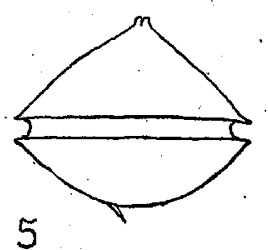
5

Diplopsalis spec.

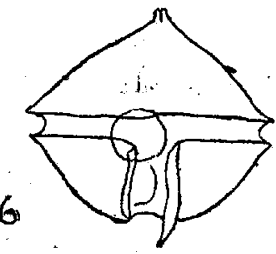

Fig. 5. Een individn van de rugzijde gezien. - Fig. 6. Een Fig. 5. Een individu van de rugzijde gezien. - Fig. 6.
ander individu van de buikzijde gezien. - Verg. 500 gel ook sterk ontwikkeld is, verschilt zij door haar meer afgeplatte, tolvormige gedaante en door haar grooter afmeting. Daar het mij tot dusverre nog niet gelukt is, de moeilijk 
waarneembare struktuur van het pantser met alle zekerheid vast te stellen, moge deze soort hier voorloopig onbenoemd blijven.

\section{GERATIUM}

14. C. hirundinella (O. F. M.) Schrank. Briefe nat. phys. ökon. Inhalts, 1802, blz. 375.

Syn. Bursaria hirundinella O. F. Müller. Anim. inf., blz. 11\%, pl. XVII, figg. 9-12.

Lichaam dorsoventraal sterk afgeplat, met 3 of 4 verschillend lange horens: één rechte, dunne aan het uiteinde afgeknotte en van een eindelingsche opening voorziene apikale horen, en 2 of 3 puntige, gesloten, rechte of gebogen antapikale horens. Pantserplaten met duidelijke netvormige struktuur; op de hoekpunten der ribben kortere of langere stekeltjes. Dwarsgroeve bijna cirkelrond, nu eens rechts-, dan linkswindend. Chromatoforen geelbruin, schijfvormig, kern ovaal, geen stigma.

Lengte: $100-200 \mu$.

Vindplaatsen: Zwanenwater, Kortenhoefsche plassen, Vecht, Abcouder Meer, Pikmeer, Sneeker Meer, Langweerder Wielen, Tjeukemeer, Singelgracht te Leeuwarden, zomer en herfst, in het netplankton, meestal sporadisch, alleen in de beide eerstgenoemde wateren soms zeer talrijk.

Een uiterst variabele soort, die tengevolge van haar grootte gemakkelijk gevangen wordt en in de planktonmonsters niet licht over het hoofd wordt gezien. Zij schijnt zich het meest in volkomen zoet water thuis te gevoelen en komt dan ook in het Oosten en Zuiden van ons land veel algemeener en in grooter aantal voor, dan in het door mij meer in het bijzonder onderzochte gebied.

(De verwante soort $C$. curvirostre Huitf.-Kaas, met sikkelvormig gebogen apikale horen, die door ons tot dusverre slechts in een watertje bij Malden in Gelderland werd aangetroffen, schijnt in dit gebied te ontbreken, evenals de korthoornige $C$. cornutum.(Ehrb.) Clap. et Lachm.).

De meeste onzer zoetwater-Peridineeën zijn bewoners van ondiepe wateren - vijvers, poelen en plassen - waar zij nu eens tusschen plankton, dan weer meer in het open water worden aangetroffen. Zij moeten derhalve tot de zoogenaamde semi-pelagische vormen worden gerekend. Een uitzonderiug maakt slechts Ceratium hirundinella, die een echte pelagische soort is en bij voorkeur in helder water leeft. In meren met groote Cyanophyeeën-maxima komt zij volgens Wesenberg Lund (11) gewoonlijk niet tot ontwikkeling: wellicht is het aan deze omstandigheid toe te schrijven, dat ook bij ons in de minder heldere, Cyanophyeeën-rijke wateren, zooals het Spaarne, de Poel bij Amstelveen e. d. C. hirundinella ontbreekt of slechts sporadisch wordt aangetroffen.

Van deze soort is ook bekend, dat zij een groote verspreiding heeft: zij wordt in hijna alle zoetwater-planktonlijsten vermeld. Omtrent het voorkomen en de verspreiding der overige soorten is uitteraard nog slechts weinig bekend. Eerst door een stelselmatiger onderzoek van het zoetwater-nannoplankton kan hieromtrent meer licht worden verspreid. Zooals uit de literatuur-opgave blijkt, komen de meeste der bij ons gevonden soorten ook in Duitschland voor.

Nigtevecht, 1 December 1918. 
LITERAT U UR - O P $($ A A VE

Behalve de bekende werken van Ehrenbergh, von STzis, Bütschli heb ik de navolgende bij mijn bewerking geraadpleegd:

1. Apstern, K., Das Süsswasserplankton. Kiel-Leipzig, 1896.

2. Breemen, P. J. van, Plankton van Noordzee en Zuiderzee. Akad. Proefschr. Leiden, 1905.

3. Huttreldt-Kaas, H., Die limnetischen Peridineen in norwegischen Binnenseen. Christiania, 1900.

4. Lemmermanx, E., Algen. I. - Kryptogamenflora der Mark Brandenburg. Leipzig, 1910.

5. Ostenyeld, C. H., Beiträge zur Kenntnis der Algenflora des Kossogol-Beckens in der nordwestlichen Mongolei, mit spezieller Berücksichtigung des Phytoplanktons. - Hedwigia XLVI, 1907.

6. Paulsen, O., Peridiniales. - Nordisches Plankton XVIII, 1908.

7. Pénard, E., Les Péridiniacées du Léman. Genève, 1891.

8. ReneкE, H. C., Plankton-onderzoekingen in het Zwanenwater bij Callantsoog. Haarlem, 1903.

9. Schilding, A. J., Die Süsswasser-Peridineen. Inaug. Diss. Marburg, 1891.

10. - Dinoflagellatae (Peridineae). - Süsswasserflora Deutschlands, Oesterreichs und der Schweiz, herausgegeben von A. PAscier. Heft 3. Jena, 1913.

11. Wesenderg-Lund, C., Studier over de Danske Söers Plankton. Specielle Del. Kjöbenhavn, 1904.

12. Zacharias, O., Biologische Charakteristik des Klinkerteichs zu Plön. - Forschungsberichte Plön X, 1903. 